\title{
Efemérides e discursos políticos nos Boletins da Polícia Militar do Rio de Janeiro (1964-1969)
}

\author{
Ephemeris and political discourses in the police report of the Rio de Janeiro Military \\ Police (1964-1969)
}

\author{
Vivian Zampa \\ Doutora em História Política \\ Professora da Univervidade Salgado de Oliveria e do Colégio de \\ Aplicação da Universidade do Estado do Rio de Janeiro \\ vivianzampa@gmail.com
}

Resumo: Este artigo tem por objetivo discutir os discursos políticos presentes nos Boletins da Polícia Militar do Rio de Janeiro entre 1964 e 1969. Os Boletins da PMRJ são documentos administrativos, de produção contínua nos dias úteis, com diferentes informes. Durante o regime militar, a Polícia Militar reproduziu discursos que vinham sendo propagados pelo Exército pelo menos desde os anos de 1930 e desenvolveu textos com as mesmas dimensões. A elaboração de um discurso que motivasse a aceitabilidade e, mais ainda, a necessidade do regime militar entre os membros das PMs, tornou-se uma peça fundamental no processo de criação de uma consciência coletiva sobre os "inimigos" do período e de defesa da "democracia" expressas nas ações das Forças Armadas.

Palavras-chave: Polícia Militar do Rio de Janeiro; discursos políticos; Regime Militar.
Abstract: The goal of the present article is discuss about the political speeches in the police report of Rio de Janeiro Military Police (1964-1969). The police reports of PMRJ are administrative documents, of continuous production on working days, with varied reports. During the military regime, the military police reproduce the speeches that used to be propagated by the arm since, at least, over the years 1930. The elaboration of a discourse that motivate the acceptability and, even more, the necessity of military regime between the members of PMs, becomes, in that period, fundamental component in the process of consciousness collective creation about the "enemy" and the defense of democracy expressed in the Armed Forces.

Keywords: Rio de Janeiro Military Police; political discourses; Military Regime. 
Dois dias após a ação militar que depôs o presidente João Goulart, o Boletim da Polícia Militar do Rio de Janeiro ${ }^{1}$ saudava o movimento, ressaltando a participação de parte do agrupamento no mesmo, além de solicitar registros para o seu efetivo

Considerando que, desde 1809, vem esta PM participando de fatos históricos da Nação.

Considerando, porém, que muitos deles esta Corporação não dispõe de documentação precisa, o que tem dificultado, em alguns casos, impossibilitado o seu registro histórico.

Considerando, finalmente, que os últimos acontecimentos devem ficar, com a máxima exatidão, em documentos e serem guardados, no Arquivo Geral, junto a outros tantos referentes à gloriosa história de nossa Milícia, para apreciação equilibrada da posteridade;

Determina que os oficiais que participaram, diretamente dos últimos acontecimentos, verdadeiramente históricos, porque passou nossa pátria, remetam à SPM, até o dia 10 do iniciante mês, relatório datilografado, em duas vias, devidamente assinadas, em que sejam narrados, de forma clara, minuciosamente e sem comentários, os fatos que tomaram parte (PMRJ, BOL $\left.n^{\circ} .62,02 / 04 / 1964\right)$.

Os Boletins redigidos pela PMRJ (BOL PMRJ) são documentos administrativos, de produção contínua nos dias úteis, com informes para o corpo policial sobre práticas institucionais ligadas a nomeações, promoções, lotações e punições, entre outros, indicados em seções como: Assuntos Gerais e Administrativos; Mudança de Escala; Movimento de Viaturas e Atos do Secretário de Segurança Pública. ${ }^{2}$

É justamente nessa última seção e também nas Ordens do Dia, que são reproduzidos discursos que fogem aos aspectos burocráticos e se vinculam a temas mais gerais, incluindo o posicionamento político da Instituição em diferentes conjunturas. Durante o regime militar iniciado em 1964, como uma força legítima de coação do

\footnotetext{
${ }^{1}$ Durante o período republicano, a atual Polícia Militar do Estado do Rio de Janeiro recebeu diferentes denominações em função das conjunturas políticas nas quais esteve inserida. De Polícia Militar do Distrito Federal (PMDF), desde 1889, passou a se chamar Polícia Militar do Estado da Guanabara (PMEG), após a transferência da capital para Brasília em 1960. Em março de 1975, por ocasião da Fusão dos estados da Guanabara e do Rio de Janeiro, ocorreu a unificação das duas corporações policiais militares que atuavam no estado - a Polícia Militar do Estado da Guanabara e a Polícia Militar do Rio de Janeiro - dando origem, dessa forma, à Polícia Militar do Estado do Rio de Janeiro (PMERJ). Como o recorte do artigo comporta o período em que recebeu pelo menos três denominações, houve uma opção, a título de normatização e sem prejuízos ao conteúdo do mesmo, de identificá-la como Polícia Militar do Rio de Janeiro (PMRJ).

${ }^{2}$ Ressalta-se que essa organização se refere à época trabalhada no presente artigo.
} 
Estado, a Polícia Militar reproduziu, nessas falas, o discurso anticomunista que vinha sendo propagado pelo Exército pelo menos desde os anos de 1930, seja por meio da transcrição de suas Ordens do Dia ou por textos escritos pelos próprios Comandantes da PM.

O anticomunismo, segundo Rodrigo Patto Sá Motta é a postura de indivíduos e grupos dedicados à luta contra o comunismo, seja pela palavra ou pela ação. Logo, a base de sua atuação estaria centrada em uma atitude de recusa expressa ao projeto comunista, entendido, no século $\mathrm{XX}$, como a síntese marxista-leninista que deu origem ao bolchevismo e ao modelo soviético (MOTTA, 2002: XIX)

$\mathrm{Na}$ primeira metade do século $\mathrm{XX}$, o anticomunismo congregou grupos de diversas naturezas políticas e até mesmo opostos, como os liberais e os fascistas, que em determinados momentos uniram-se, em um grande discurso, no projeto maior de combate ao comunismo.

Mas, em que pese a heterogeneidade, ou talvez por cauda dela, o fato é que o anticomunismo tornou-se uma força decisiva nas lutas políticas do mundo contemporâneo, alimentado e estimulado pela dinâmica do inimigo que era a sua razão de ser, o comunismo. [...] Durante os cerca de setenta anos compreendidos entre a Revolução de outubro de 1917 e a crise do socialismo real ocorrida na virada da década de 1980 para 1990, o comunismo tornou-se muito mais que um espectro (MOTTA, 2002: XIX).

Para Maria Celina D’Araújo, Gláucio Soares e Celso Castro, durante as entrevistas realizadas para o livro Visões do Golpe: a memória militar sobre 1964, o papel que os depoentes militares atribuem ao anticomunismo para a explicação do golpe é central

A origem histórica desse sentimento anticomunista, disseminado nas Forças Armadas, é a revolta Comunista de 1935. O efeito emocional do que foi visto como uma imperdoável traição perdurou por décadas, ritualizando-se na peregrinação anual ao monumento aos mortos na "intentona" (D’ARAÚJO, SOARES \&CASTRO, 1994: 11).

Ainda segundo os autores, esse sentimento era evidenciado na construção de falas que aproximavam o comunismo a práticas "ameaçadoras" e "traiçoeiras", que tentaram invadir os quartéis no passado e novamente representavam uma ameaça nos anos 60. 
Além disso, o discurso militar anticomunista era ampliado quando associado à conjuntura internacional do pós-guerra, e a leitura de que sua estratégia passou a centrar-se na guerra subversiva, ou revolucionária, desenvolvida no interior dos países capitalistas (D’ARAÚJO, SOARES \$ CASTRO, 1994: 12).

A análise dos discursos militares, publicados no período em manuais, livros e Ordens do Dia, se torna fundamental para a compreensão do quanto foram úteis no engajamento de militares para a organização do golpe, bem como em suas posteriores ações. Ao examinar a linguagem como um instrumento de interação social, Bakhtin argumenta que o sujeito produtor passa a ocupar um lugar de destaque em diferentes situações, já que é a partir dele que se produz a compreensão de variadas relações sóciohistóricas. Tal sujeito, dessa forma, constrói enunciados que expressam acontecimentos que, necessariamente, exigem: uma determinada situação histórica, a identificação dos atores sociais, o compartilhamento de uma mesma cultura, e, por fim, o estabelecimento de um diálogo (BAKTHIN, 1997: 283-284).

Transpondo essa noção aos Boletins da PMRJ ora analisados, é possível pontuálos a partir da compreensão de que: foram produzidos durante o regime militar, retratando a fala de Comandantes dessa Instituição e/ou do Exército, em concomitância com a publicação de Leis e Decretos lançados no período e que se inserem dentro de uma cultura, sobretudo, anticomunista, a fim de compartilhar valores e conceitos considerados fundamentais, para toda a Corporação.

A leitura dos Boletins da PMRJ possibilita a identificação e o estabelecimento de uma determinada recorrência de palavras e do discurso anticomunista, além do entendimento do quanto foram trabalhados e disseminados na Instituição, de forma a construir os padrões de um novo e perigoso "inimigo" a ser combatido pelos Policiais Militares, uma vez que

[...] a palavra penetra literalmente em todas as relações entre indivíduos, nas relações de colaboração, nas de base ideológica, nos encontros fortuitos da vida cotidiana, nas relações de caráter político, etc. As palavras são tecidas a partir de uma multidão de fios ideológicos e servem de trama a todas as relações sociais em todos os domínios (BAKTHIN, 1997: 41). 
Nessa perspectiva, o maior número de discursos anticomunistas e legitimadores da "Revolução de 1964" aparecem, principalmente, em quatro datas exaustivamente referendadas por essa Corporação: 31 de março, aniversário do movimento de 1964, 21 de abril, dia de Tiradentes, patrono das Polícias, 15 de novembro, data da Proclamação da República e 27 de novembro, em referência ao episódio da Insurreição Comunista de 1935, chamada de forma pejorativa de "Intentona Comunista".

Nessas datas, de grande significado para os militares, as homenagens à "gloriosa revolução de 1964", ao patrono das Polícias e herói cívico do Brasil, à Proclamação da República e à memória dos militares assassinados pela "Intentona Comunista", constituíam importantes espaços para a construção de um discurso que tanto reforçava a identidade institucional quanto possibilitava uma reflexão sobre o período vivido associado, de forma conveniente, aos referidos fatos.

Se nos dias 31 de março, 15 e 27 de novembro evidenciam-se a alternância entre o discurso dos Comandantes Gerais da PMRJ e a reprodução das Ordens do Dia do Exército, tendo em vista a relevância dessas datas para a referida Corporação, o dia 21 de abril marca a publicação exclusiva de textos dos então Comandantes Gerais da Polícia Militar, voltando-se especialmente às demandas e à realidade dessa Corporação em um dia considerado muito caro - de seu grande patrono - que fora oficializado desde 1946.

[...] Considerando que a ação do indômito protomártir da Independência, como o soldado da Lei e da Ordem, deve constituir um paradigma para os que hoje exercem funções de defesa da segurança pública, como sejam as polícias civis e militares, às quais incumbe a manutenção da ordem e resguardo das instituições:

Usando da atribuição que lhe confere o art. 180 da Constituição,

\section{DECRETA:}

Artigo único. Fica instituído o Dia das Polícias Civis e Militares que será, comemorado todos os anos a 21 de Abril, data em que as referidas corporações em todo o país realizarão comemorações cívicas que terão como patrono o grande vulto da Inconfidência Mineira.

Rio de Janeiro, 29 de Abril de 1946, $125^{\circ}$ da Independência e 58 da República (BRASIL, 1946). 
Conforme fora estabelecido pelo Decreto-Lei 9208, a opção por Tiradentes como o patrono das Polícias anunciava, acima de tudo, o herói mineiro como um exemplo a ser seguido pelos homens da Lei e da ordem. Embora, desde o início da República, Tiradentes tenha sido escolhido e construído pelos militares em sendo um herói que os representava (Cf. CARVALHO, 1998), somente no início do regime militar, no governo de Castelo Branco, é que o "grande homem militar" Tiradentes, foi declarado patrono cívico da Nação Brasileira".3

Segundo Raoul Girardet, os processos de heroificação implicam em certa adequação da personalidade do salvador às necessidades da sociedade em um determinado momento de sua história (GIRARDET, 1987. p. 82-83). A imagem do herói, nessa perspectiva é reconstruída tanto devido às necessidades do Estado quanto das Instituições que o elegem. No caso das Polícias e, em inícios do regime militar liderado pelo Exército, a escolha e a reafirmação do mito de Tiradentes instigava policiais e militares a seguirem seu modelo exemplar na lógica de salvação da sociedade, que se apresentava naquele momento.

Uma República que foi instituída pelas Forças Militares construiu, assim, um herói que representa o militar, o religioso, o povo e a masculinidade. As múltiplas faces desse herói possibilitam, como dissemos acima, sua constante reconstrução e adaptação às diferentes realidades institucionais, políticas e sociais. Para os militares, a identidade do herói assume principalmente a face do Alferes, o soldado que morreu em defesa da Pátria. Sua imagem é a de um homem que lutou pela liberdade da Pátria contra os tiranos portugueses. (SCHACTAE, 2009: 157).

Não por acaso, no dia 21 de abril foram publicados inúmeros textos clamando os policiais militares a se esmerarem, como verdadeiros heróis, na empreitada contra a "bolchevização" e os males que afetavam o país.

\section{Herói Tiradentes:}

Estejas certo de utilidade de teu sacrifício.

Dentro em pouco desfilarão os teus afilhados e redes vislumbrar em cada homem, em cada arma, em cada peito, um instrumento dos teus ideais.

\footnotetext{
3 Tiradentes foi declarado Patrono Cívico da Nação Brasileira, através da Lei, no 4897, de 09 de dezembro de 1965 (BRASIL, 1965).
} 
Tua imagem nos guia e conforta em todas as nossas ações.

Na calada da noite agiganta-se a figura do soldado da Polícia Militar, zelando pelo bem estar público, para que a propriedade tenha significado real e que os trabalhadores desfrutem de um justo e merecido repouso.

A alva bandeira da liberdade, que empunhaste, é o estandarte que trazemos em mente, toda vez que se torna necessário empunharmos nossas armas para libertação do Brasil das tendências bolchevizantes, que se chocam com a índole cristã de nosso povo.

Nossa presença aqui não é ato de rotina, mas a confirmação solene de que a Polícia Militar, unida, com um só pensamento, esteve o estará presente em todos os momentos de grave crise nacional, sempre que chamada, tendo o teu ideal por paradigma.

Teu sacrifício há de inspirar as nossas decisões, para que sejamos, como temos sido, dignos de ter-te como padrinho.

Estejas certo que esta terra dadivosa saberá cumprir a sua missão histórica de guardiã dos ideais que espalhastes pelos quatro cantos do nosso Brasil.

Fica certo que tudo fazemos para que nossas ações diárias na calada da noite sejam flores que depositamos aos pés do excelso bronze em que estás esculpido.

Djalma de Andrade Jacó - Coronel Comandante Geral (PMRJ. BOL N ${ }^{\circ}$ 081, 21/04/1966).

De uma forma geral, o discurso acima foi reproduzido em diferentes momentos do regime militar, acentuando determinados conceitos e noções mais próximos das conjunturas em que se inseriam como as de revoltas estudantis, sequestros ou greves, e outros.

Nesse sentido, no dia 31 de março de 1965, fora publicado no BOLPMRJ um texto homenageando o primeiro aniversário da "Revolução Redentora". Com referências à Grécia Antiga e às solenidades que consagravam os méritos, elogiavam os valores e glorificavam as virtudes. O Comandante Geral Édson Moura Freitas destacava que tais datas não referendavam apenas o culto do passado ou o enobrecimento do presente, mas a afirmação de uma "esperança entronizada na história". A intervenção militar de 1964, de acordo com o Coronel, tornava-se ainda mais especial, porque contou com a participação da Polícia Militar. 
Aos vos dirigir estas palavras, o vosso comandante geral sente o coração referto de profunda satisfação, pois esta corporação soube ser digna das suas tradições, cumprindo o seu dever com decidida galhardia, sem que se pudesse distinguir, dentre os milicianos guanabarianos, quais os veteranos e quais os neófitos tal a homogeneidade com que se comportaram oficiais e praças, em atendimento a imposição histórica daquele dia inesquecível. Este comando sente, nesta comemoração, aquela mesma emoção que lhe tomou o coração e a alma no momento histórico em que lhe foi dada a notícia de que o ideal dos bons havia vencido. Que a pátria estava livre dos seus algozes vermelhos.

Recordai-vos sempre, meus comandos, das vicissitudes daqueles momentos trágicos e esta lembrança vos fará amadurecer no coração o espírito espartano que é vosso e do qual tão forte e evidente prova soubestes dar (PMRJ, BOL n'61, 31/03/1965).

Na menção alusiva ao primeiro aniversário do Golpe de 1964, o Comandante Geral da Polícia Militar da Guanabara procurou identificar esse momento com o heroísmo de seus protagonistas, dentre os quais estavam os integrantes da sua Corporação, diante do combate ao "inimigo vermelho" e de defesa das instituições republicanas. Há que se destacar que, nesse momento, o primeiro Ato Institucional já havia sido decretado e o discurso procurava, acima de tudo, justificar os momentos iniciais dos governos militares, desqualificando o governo Goulart e incorporando a Polícia Militar à nova ordem que se apresentava. É nesse sentido, que nos festejos de final de ano de 1965, mais uma vez são encontradas essas menções.

Foi esse amor à ordem que levou a Corporação a equilibrar-se em meio a onda de anarquia que invadia o país e a qual já não resistiam setores tradicionais disciplinados das Forças Armadas.

Foi ainda neste espírito disciplinado que fez a Polícia Militar, na Revolução de 31 de março, marchar, na primeira hora, unida e sem discrepância, coesa e decidida, ao lado das Forças Armadas que resolviam atalhar o caminho do comunismo na nossa Pátria (PMRJ, BOL n²39, 20/12/1965).

Nos primeiros anos do regime militar, portanto, a maior preocupação demonstrada foi a de construir um consenso no interior da Corporação em relação ao combate ao comunismo e aos acertos da nova ordem política que se iniciava, associando-a 
diretamente ao fortalecimento das instituições democráticas. Cabe ressaltar que a batalha contra o "inimigo vermelho" era justificada a partir do uso de maniqueísmos expressos em distinções como a luta entre o bem e o mal, a ordem e o caos, o lícito e o ilícito, de forma a destacar antíteses que, por um lado, traçavam o perfil do inimigo político da época e, por outro e de forma oposta, do grande serviço prestado pelos militares à sociedade, livrando-a desse "perigo".

Os anos de 1968 e 1969 tornaram-se emblemáticos sob o ponto de vista das publicações nos Boletins da PMRJ, com a incursão de temas que se ligavam diretamente às questões políticas. A conjuntura desse período, a princípio, foi marcada pelo surgimento de resistências à nova ordem e às primeiras articulações políticas formais contrárias ao fim dos partidos políticos, como fora decretado pelo AI-2 em 1965. Essa época também foi marcada por organizações que iniciaram um confronto mais direto e, por vezes, violento, contra o regime que progressivamente tornava-se mais repressivo. Assim, no dia 31 de março de 1968, a referência ao aniversário da "Revolução Redentora" não foi feita pelo Comandante Geral da Polícia Militar, mas transcrita da Ordem do Dia do Ministério do Exército.

"O 4 Aniversário da Revolução de Março - 31 de março de 1968"

É com legítimo orgulho cívico e redobrada confiança que o Exército festeja nesta data, em todos os seus quartéis, o quarto aniversário da Revolução de 31 de março.

A consciência da sua verdadeira e grande significação já é, agora, fortalecida, passados apenas quatro anos, pela auspiciosa transformação que tão rapidamente se processou na vida nacional, antes aviltada e tumultuada.

Vemos, hoje, o Brasil trabalhando e produzindo em ambiente de ordem, com o restabelecimento e a dignificação do princípio da autoridade, para recuperarse, pelo esforço solidário do governo e do povo, unidos no mesmo alto e patriótico propósito de recolocá-lo, definitiva e firmemente, no caminho dos seus verdadeiros destinos. [...]

Foi uma reação do espírito do povo e das Forças Armadas, que agora se prolonga no grande esforço pela recuperação nacional, sob os auspícios e com o decidido empenho deste segundo governo. [...]

Gen. Ex. Aurélio de Lyra Tavares - Ministro do Exército (PMRJ, BOL $\left.\mathrm{n}^{\circ} 225,15 / 11 / 1968\right)$. 
A ordem do dia reproduzida procurava destacar o ambiente de estabilidade e a necessidade do uso da autoridade para mantê-la. O segundo governo mencionado nesse texto foi o do presidente Costa e Silva. Durante sua gestão os setores de informação e de repressão que existiam desde o governo Vargas foram mais fortalecidos. Uma repressão que cresceu ainda mais, junto a movimentos de rebeldia que agitaram os estudantes em diferentes países do mundo.

Nesse período, a maior manifestação contra o governo militar aconteceu em junho de 1968, quando a Passeata dos Cem Mil, liderada pela União Nacional dos Estudantes (UNE), por intelectuais e por artistas, ocupou o centro da cidade do Rio de Janeiro, dando sequência a uma série de enfrentamentos entre os manifestantes e as forças de repressão nos principais centros do país. Não por acaso, o BOL PMRJ desse ano conferiu grande destaque à chamada "Intentona Comunista", relembrando o perigo desse agrupamento político, instado pela "violência" e pela "desordem", de forma a associá-la aos movimentos comunistas que se organizavam à época.

IV -27 de novembro

A data que hoje transcorre faz-nos lembrar amargamente, que há 33 anos atrás, o sangue precioso dos nossos valorosos companheiros, jorravam aos borbotões sobre, e em defesa do solo sagrado da mãe pátria das instituições da família brasileira.

Precisamente a 17 de novembro de 1935, irrompia em NATAL e RECIFE, um movimento covarde de cunho comunista, com ramificações no Rio de Janeiro. Aqui, dez dias após, precisamente no dia 27, porém, prontamente sufocado, graças à imediata e providencial intervenção do governo, tendo na região nordestina uma duração efêmera. [...]

\footnotetext{
${ }^{4}$ A expressão "Intentona Comunista" significa "intento louco ou plano insensato", indicando a intenção de menosprezar as primeiras ações militares com participação comunista no Brasil em 1935. O referido movimento, do qual participaram militares identificados com o tenentismo, organizações sindicais e estudantis, profissionais liberais e comunistas, teve Luiz Carlos Prestes, que aderira ao comunismo, como presidente de honra. Inserido no contexto de críticas ao autoritarismo do governo Vargas, ao crescimento do Integralismo no Brasil e de criação da Aliança Nacional Libertadora (ANL), uma ampla frente política em defesa das liberdades democráticas no período, contou com o auxílio de Moscou naorganização de uma ação revolucionária, com levantes militares em diferentes regiões do país. A saber: em Natal, no dia 23 de novembro, em Recife, no dia seguinte, e no Rio de Janeiro na madrugada do dia 27 do mesmo mês. Estando restrito a três cidades e não contando com a adesão militar e do operariado esperada, tais movimentos foram brutalmente reprimidos e relembrados ano a ano, no mês de novembro, no Exército, como um grande exemplo de traição da Instituição por militares comunistas. Ver: ZAMPA, 2017: 108-109.
} 
No Recife; as tropas do Exército e brigada militar do Estado portaram-se com denodo sangue frio, preservando a ordem, garantindo a vitória ao governo e ao Brasil.

No Rio; Exército, Marinha e Polícia Militar, irmanados e comungando com o mesmo pensamento, não permitiram nem que se mostrasse ao povo a bandeira dos bolchevistas, encurralando os sublevados do $3^{\circ}$ Regimento de Infantaria e Escola de viação.

Pretendiam - não foram a Sentinela sempre atenta e vigilante de nossos soldados - com seus recursos místicos surpreendentes e violentos, que lhes são peculiares, e suas influências ideológicas, a prática de suas realizações sanguinárias, irradiando a ação agressiva e solerte, voltando as armas contra a própria pátria que um dia lhes confiou para defendê-la.

O comunismo, costumeiramente com a sua tática, já por demais conhecida, não podendo se projetar de forma concreta e ostensivamente, sequioso de voltar a atividade primitiva, infiltrando-se em todas as classes com dissimulação e hipocrisia, tenso sempre em mira os meios estudantis universitários, militares e proletários, numa ação lenta e pertinaz, corrompendo, fracionando e solapando os alicerces da disciplina e da ordem $[\ldots]$

Esta página imaculada de nossos anais, escrita nobremente com o sangue fraterno, será sempre perpetuada aos bravos de 1935, aos quais, entoaremos cânticos de louvor e glória (PMRJ, BOL nº 232, 27/11/1968).

O ano supracitado teve grande significado para a intensificação de toda uma linha anticomunista, especialmente voltada a grupos estudantis e trabalhistas, por parte da Polícia Militar. Nesse período, a Instituição operou em diferentes casos de enfrentamento contra os agrupamentos que se opunham ao regime instalado. Em um desses episódios, em março de 1968, estudantes organizaram uma passeata relâmpago contra o aumento do preço da comida de um restaurante universitário, mantido pelo governo, o Calabouço.

Os protestos estabelecidos nesse local levaram a Polícia Militar a dispersar tais estudantes, que, ao se abrigarem no restaurante, utilizaram pedaços de pau e pedras contra os policiais militares. O pretenso ataque à Embaixada dos Estados Unidos motivou a investida desses militares ao local e o comandante da tropa, o aspirante Aloísio Raposo, a atirar e matar o secundarista Edson Luís, de dezesseis anos, com um tiro no peito. O corpo do estudante, velado na Assembléia Legislativa, foi acompanhado por cerca de 
50.000 pessoas até o Cemitério São João Batista, local de seu enterro. O fato que comoveu todo o país foi acompanhado por várias manifestações contra a atuação militar no centro da cidade, chegando a um ponto máximo nos arredores da igreja da Candelária, por ocasião de sua missa de sétimo dia, quando soldados a cavalo postaram-se contra a população que a acompanhava (FREIXO, FREITAS, 2008: 26).

Nessa conjuntura de desgaste, incrementar a necessidade de combate ao inimigo tornava-se fundamental, especialmente para manter a coesão do Corpo Policial em suas próximas ações, por isso a continuidade do discurso reafirmando a necessidade de combater o maior "inimigo" do período, que já tinha mostrado sua capacidade de ação no passado, e que agora se manifestava por meio dos estudantes.

Acautelem-se, pois, contra as investidas constantes no inimigo vermelho, que nos assedia a todo momento no cotidiano.

Repudie-o, repila-o, enxote-o para longe e reprima-o com todas as forças e energia.

Basta que observemos os acontecimentos estudantis dos últimos tempos. Assim estás cumprindo o sagrado juramento que prestantes perante a pátria simbolizada no seu pavilhão de defendê-la até a morte, acatar as autoridades constituídas, preservando as instituições e autonomia do Estado (PMRJ, BOL $\left.n^{\circ} 232,27 / 11 / 1968\right)$.

A preocupação demonstrada pela Polícia Militar refletia um quadro conflituoso bem maior. Os embates entre os meios militares e civis cresceram intensivamente nesse período, atingindo seu auge quando o deputado Márcio Moreira Alves foi acusado de ter ofendido as Forças Armadas, e a Câmara dos Deputados negou-se a processá-lo. Em função desse fato e do fortalecimento dos movimentos oposicionistas, em 13 de dezembro de 1968 foi editado o Ato Institucional no 5 (AI-5), determinando o recesso do Congresso Nacional e de outros órgãos legislativos; a intervenção federal nos estados e municípios; a cassação de mandatos eletivos; a suspensão dos direitos políticos de qualquer cidadão; o fim da garantia do habeas corpus e o confisco de bens obtidos por meios ilícitos. Esse Ato e o complementar $\mathrm{n}^{\mathrm{o}} 38$ foram transcritos à íntegra no BOL PMRJ $\mathrm{n}^{\circ} 252$, de 27 de dezembro de 1968, esclarecendo, assim, à tropa, a realidade que se apresentava junto aos novos parâmetros que deveriam ser incorporados às suas atividades. 
Os desdobramentos do AI-5 também figuraram nos Boletins da Polícia Militar. Dessa forma, o BOL PMRJ N 8, de 13 de Janeiro de 1969, reproduziu os Atos do Poder Executivo referentes às cassações dos mandatos políticos

\section{IX- ATOS DO PODER EXECUTIVO - TRANSCRIÇÃO}

$[\ldots]$

4- $O$ presidente da república, no uso das atribuições que lhe confere o art $4^{\circ}$ do ato institucional $\mathrm{n}^{\circ} 5$, de 13 de dezembro de 1968, e tendo em vista indicação do conselho de segurança nacional, resolve

\section{CASSAR:}

Os mandatos eletivos federais e suspender os direitos políticos, pelo prazo de dez (10) anos, dos seguintes cidadãos:

Márcio Emmanuel Moreira Alves - deputado federal - GB

Hermano de Deus Nobre Alves - deputado federal - GB

David José Lerer - deputado federal - SP

Hélio Henrique Pereira Navarro - deputado federal - SP

GastoneRighiCuochi - deputado federal - SP

José Lurtz Sabiá - deputado federal - SP

Henrique Henkin - deputado federal - RS

Matheus José Schimdt Filho - deputado federal - RS

Renato Bayma Archer da Silva - deputado federal - MA

José Carlos Estelita Guerra - deputado federal - PE

Maurício Filgueira Ferreira Lima - suplente de deputado federal em exercício $-\mathrm{PE}$

5- O presidente da república, no uso das atribuições que lhe confere o art $4^{\circ}$ do Ato Institucional $\mathrm{N}^{\circ}$ 5, de 13 de dezembro de 1968, e tendo em vista indicação do conselho de segurança nacional, resolve

SUSPENDER OS DIREITOS POLÍTICOS:

Pelo prazo de 10 (dez) anos, do cidadão Carlos Frederico Werneck de Lacerda. Brasília, 30 de dezembro de 1968

6- $O$ presidente da república, no uso das atribuições que lhe confere o art $4^{\circ}$ do Ato Institucional № 5, de 13 de dezembro de 1968, e tendo em vista indicação do conselho de segurança nacional, resolve

\section{SUSPENDER OS DIREITOS POLÍTICOS:}

Pelo prazo de dez (10) anos, do cidadão Joaquim de Souza Neto, Desembargador-presidente do Tribunal de Justiça do Distrito Federal. 
Brasília, 30 de dezembro de 1968 (PMRJ, BOL nº 8, 13/01/1969).

Outras listas foram publicadas nos Boletins da Polícia Militar, no ano de 1969, como reflexo do Ato Institucional $n^{\circ} 5$ e da grande mudança na esfera do controle e da repressão que assolavam o país. Nessa conjuntura, atitudes radicais foram fortalecidas tanto pelo lado militar quanto pelo da oposição. O Boletim $\mathrm{N}^{\mathrm{o}} 28$, de 11 de fevereiro de 1969, transcreveu o Ato Complementar No 47, do Conselho de Segurança Nacional, que destacava o quadro de insegurança que assombrava o país a partir das práticas de elementos "subversivos" e "contra-revolucionários", que promoviam a inquietação social e a perturbação da ordem pública, com vistas à derrubada do regime. Nesse contexto, o Conselho evidenciava as seguintes atividades desenvolvidas pelos "esquerdistas":

- [...] ação perturbadora do clero "progressista";

- deterioração da ação política no congresso nacional;

- intensificação de ações ostensivas contra as instituições, praticadas pelas diferentes facções comunistas;

- empenho das organizações comunistas vinculadas a China e a Cuba nos preparativos para a condução, a curto prazo, da luta armada;

- ação das cúpulas estudantis e esquerdas, a exemplo do que ocorreu na França no sentido de minar o principio da autoridade e de motivar a população para aceitar as ocupações das faculdades e as manifestações abusivas contra os responsáveis pelos destinos do país;

- caracterização nítida do terror cultural comunista nas universidades, resultando na marginalização de diversos professores, na acomodação de um grande número de alunos e professores e na distorção dos verdadeiros postulados da democracia;

- $\quad$ veiculação maciça, pelos órgãos formadores da opinião pública, de teses contrárias aos desígnios da Revolução de 31 de março de 1964, em perfeita consonância com a estratégia do movimento comunista mundial. A imprensa, em sua grande maioria dominada pelos comunistas, representou um papel importantíssimo no quadro geral dos acontecimentos;

- campanha conduzida através da imprensa e da televisão em ligação com órgãos estrangeiros de imprensa e de outros estudos internacionais, sobre discriminação racial, visando a criar novas áreas de atritos e insatisfação com o regime e as autoridades constituídas;

- esvaziamento do impacto causado pela invasão da Tchecoeslováquia, 
através da reativação da campanha em torno do conflito do Vietnã (PMRJ, $\left.\mathrm{BOL} \mathrm{n}^{\circ} 34,21 / 02 / 1969\right)$.

Da mesma forma, era ressaltada a ação de grupos de anticomunistas extremados, que passaram a atuar, também pichando paredes, distribuindo panfletos à população e praticando outros atos que se enquadravam no esquema do terrorismo urbano. Esse agravamento de ações contra a ordem era creditado à decretação do AI-5, que teria tornado possível ao governo aprisionar, investigar e identificar os responsáveis pelo conturbado ambiente que se irradiava no país.

Os atos de violência praticados por grupos de esquerda, como os atentados terroristas, assaltos a bancos e a quartéis do exército, roubos de uniformes, armas e equipamentos militares também eram expostos, oferecendo um indicativo daquilo que mereceria maior atenção e ação da Polícia Militar:

Como exemplo dessas atividades subversivas e contra-revolucionárias destacam-se:

- apreensão de grande número de armas, explosivos, material de propaganda e pregação ideológica comunista, manuais e folhetos de instrução, resultante da diligência policial, com apoio de elementos do II exército, levada a efeito no conjunto residencial da Universidade de São Paulo (CRUSP);

- prosseguimento dos assaltos a bancos, principalmente nos Estados de São Paulo, Minas Gerais e Rio de Janeiro. Até o presente, já foram realizados cerca de sessenta assaltos e roubados da ordem de 2,1 milhões de cruzeiros novos;

- realização de novos atentados terroristas com maior incidência na Guanabara e em São Paulo;

- confirmação da atividade da política operária (POLOP - dissidência do PCB apologista da ação violenta) em Belo Horizonte, com ramificações em São Paulo, Guanabara e Niterói;

- atividades de elementos da Ala Marighela em Brasília, com ramificações em São Paulo, Minas Gerais, Guanabara, Rio de Janeiro e Ceará;

- finalmente, o furto praticado pelo cap. CARLOS LAMARCA, em sua própria unidade, abrangendo um elevado número de armas de guerra e de peças de uniformes, além de munições e explosivos o que comprova a existência de uma bem montada trama comunista e constitui traição, ignomia, crime infamante e ação deletória, sem precedentes em nosso exército (PMRJ, BOL $n^{\circ} 34,21 / 02 / 1969$ ). 
A partir desse período, é possível verificar uma preocupação direta da Polícia Militar com a teorização sobre o combate ao comunismo, tanto nos cursos de aperfeiçoamento dos seus quadros de oficiais e nos respectivos trabalhos de conclusão redigidos - tais como o do Capitão Ricardo Frazão do Nascimento, sobre a Guerra revolucionária (1968), e o do Capitão Jorge D'albuquerque e Castro, sobre o Emprego das polícias militares na luta contra a guerra revolucionária (1968), por exemplo quanto nos discursos reproduzidos nos Boletins da PMRJ.

A análise dos discursos dos Comandantes da PMRJ em datas consideradas cruciais para a Instituição, durante o regime militar, permite-nos compreendê-los como um dos elementos mais trabalhados para a criação das bases de combate aos crimes políticos. A elaboração de um discurso que motivasse a aceitabilidade e, mais ainda, a necessidade do regime militar entre os membros das PMs, tornou-se, portanto, uma peça fundamental no processo de criação de uma consciência coletiva sobre os "inimigos" do período e de defesa da "democracia" expressas nas ações de dominação das Forças Armadas.

\section{Fontes}

BRASIL. Decreto-Lei No 9.208, de 29 de abril de 1946. Disponível em: <http://www.planalto.gov.br>. Acesso em: 22 jun. 2013.

BRASIL. Lei, $\mathrm{n}^{\mathrm{o}}$ 4897, de 09 de dezembro de 1965. Disponível em: <http://www.planalto.gov.br>. Acesso em: 22 jun. 2013.

CASTRO, Jorge D' Albuquerque e (1968). Emprego das polícias militares na luta contra a guerra revolucionária. Monografia apresentada ao Centro de Aperfeiçoamento de Oficiais. Rio de Janeiro. (Academia de Polícia Militar D. João VI).

NASCIMENTO, Ricardo Frazão do (1968). Guerra revolucionária - origens, características, objetivo, desenvolvimento, técnicas e táticas revolucionárias. Monografia apresentada ao Centro de Aperfeiçoamento de Oficiais. Rio de Janeiro. (Academia de Polícia Militar D. João VI).

PMRJ, BOL nº. 62, 02/04/1964. (Arquivo da Polícia Militar do Estado do Rio de Janeiro).

PMRJ, BOL n61, 31/03/1965. (Arquivo da Polícia Militar do Estado do Rio de Janeiro).

PMRJ, BOL n²39, 20/12/1965. (Arquivo da Polícia Militar do Estado do Rio de Janeiro).

PMRJ. BOL nº 081, 21/04/1966. (Arquivo da Polícia Militar do Estado do Rio de Janeiro).

PMRJ, BOL no 225, 15/11/1968. (Arquivo da Polícia Militar do Estado do Rio de Janeiro).

PMRJ, BOL no 232, 27/11/1968. (Arquivo da Polícia Militar do Estado do Rio de Janeiro).

PMRJ, BOL no 8, 13/01/1969. (Arquivo da Polícia Militar do Estado do Rio de Janeiro). 
PMRJ, BOL no 34, 21/02/1969. (Arquivo da Polícia Militar do Estado do Rio de Janeiro).

\section{Referências Bibliográficas}

BAKTHIN, Mikail (1997). Estética da criação verbal. São Paulo: Martins Fontes.

BORGES FILHO, Nilson (2007). "A Doutrina de Segurança Nacional e os governos militares”. In: FERREIRA, Jorge; DELGADO, Lucília (Orgs.). O Brasil Republicano. O Tempo da Ditadura. Rio de Janeiro: Civilização Brasileira.

CARVALHO, José Murilo de (1998). A formação das almas: o imaginário da República no Brasil. São Paulo: Cia das Letras.

D’ARAÚJO, Maria Celina, SOARES, Gláucio Dillon e CASTRO, Celso (1994). Visões do Golpe: a memória militar sobre 1964. Rio de Janeiro: Relume-Dumará.

FREIXO, Adriano de e FREITAS, Jacqueline Ventapane (2008). "Mas veio o tempo negro e a força fez comigo; o mal que a força sempre faz - O Brasil do AI-5". IN: MUNTEAL FILHO, Oswaldo, FREIXO, Adriano de e FREITAS, Jacqueline Ventapane (orgs.). "Tempo negro, temperatura sufocante": Estado e Sociedade no Brasil do AI-5. Rio de Janeiro: PUC-Rio; Contraponto.

GIRARDET, Raoul (1987). Mitos e mitologias políticas. São Paulo: Companhia das Letras.

MENEZES, Lená Medeiros de (2000). Tramas do mal: a revolução de outubro no plano das representações (1917-1921). Rio de Janeiro, UERJ, mimeo.

MOTTA, Rodrigo Patto Sá (2002). Em guarda contra o perigo vermelho. $O$ anticomunismo no Brasil. São Paulo: Perspectiva; FAPESP.

RIBEIRO, Jayme Fernandes (2011). Os Combatentes da paz: Os comunistas brasileiros e as campanhas pacifistas dos anos 1950. Rio de Janeiro: 7 letras.

SCHACTAE, Andréa Mazurok (2009). “As comemorações de Tiradentes: memória e identidade de gênero na Polícia Militar do Paraná”. In: Revista de História Regional 14(2): 154-177.

ZAMPA, Vivian (2017). "Um levante comunista". In: FIGUEIREDO, Luciano; MARTINS, Ana Cecilia Impellizieri. (Org.). História do Brasil em 100 fotografias. Rio de Janeiro: Bazar do Tempo.

- Poder Político e Monopólio da Violência: a militarização da Polícia do Rio de Janeiro entre 1964 e 1985 (2014). Tese (doutorado), Universidade do Estado do Rio de Janeiro. Instituto de Filosofia e Ciências Humanas.

. "O período Republicano"(2010). In: LEAL, Ana Beatriz, SILVA, Ibis Pereira e MUNTEAL FILHO, Oswaldo. 200 Anos - Polícia Militar do Estado do Rio de Janeiro. Rio de Janeiro: Editora PUC/RJ.

Artigo recebido em 19 de abril de 2018.

Aprovado em 21 de maio de 2018. 